\title{
OCCUPATIONAL STRESS OF EMERGENCY WORKERS IN GAUTENG
}

\author{
J.L.P. NAUDÉ \\ S. ROTHMANN \\ WorkWell, Research Unit for People, Policy and Performance, \\ Faculty of Economic \& Management Sciences \\ $P U$ for $C H E$
}

\begin{abstract}
The objectives of this study were to determine the construct validity, internal consistency, construct equivalence and item bias of the Emergency Worker Stress Inventory (EWSI) and to identify occupational stressors for emergency workers. A cross-sectional survey design was used. An accidental sample $(N=405)$ of emergency workers in Gauteng was used. The EWSI was developed as a measuring instrument and administered together with a biographical questionnaire. Three internally consistent stress factors, namely Lack of Resources, Job Demands and Inherent Emergency Work Stressors were extracted. Low structural equivalence regarding perceived stressors was detected for the Nguni-language group. No practically significant differences were found between occupational stressors of emergency workers in different positions and language groups.
\end{abstract}

\section{OPSOMMING}

Die doelstellings van hierdie navorsing was om die konstrukgeldigheid, interne konsekwentheid, konstrukekwivalensie en itemsydigheid van die Nooddienswerker Stresvraelys (NWSV) te bepaal en beroepstressore vir nooddienswerkers te identifiseer. 'n Dwarssnee opname-ontwerp is gebruik. Die studiepopulasie is met behulp van 'n beskikbaarheidsteekproef $(N=405)$ van nooddienswerkers in Gauteng verkry. Die NWSV is ontwikkel vir die studie en saam met 'n biografiese vraelys afgeneem. Drie interne konsekwente stresfaktore, naamlik Tekort aan Hulpbronne, Poseise en Inherente Nooddiens Stressore is onttrek. Lae konstrukekwivalensie is ten opsigte van waargenome stressore vir die Nguni taalgroep gevind. Geen prakties betekenisvolle verskille is tussen die beroepstressore van nooddienswerkers in verskillende posisies en taalgroepe gevind nie.

Emergency work has been identified as one of the most stressful work environments (Phipps, 1988; Whitley, Gallery, Allison \& Revicki, 1989; Young \& Cooper, 1995). Also, emergency workers tend to experience high levels of stress both in their work and their family lives (Anshel, 2000; Beaton, Murphy, Pike \& Corneil, 1997; Violanti \& Paton, 1999). According to Marmar, Weiss, Metzler, Ronfeldt and Foreman (1996) and Mitchell and Dyregrov (1993) emergency workers such as paramedics demonstrate higher levels of psychological stress which are already elevated above the general population. The demands that these emergency workers are exposed to lead to a range of social, physical and psychological responses which may be extremely stressful and threatening to their wellbeing (Moran \& Britton, 1994).

The voluminous body of stress literature is quite clear about the negative effects of occupational stress. These effects include impaired performance or reduction in productivity, diminishing levels of customer service, health problems, absenteeism, turnover, industrial accidents, alcohol and drug usage and purposefully destructive behaviours (e.g. spreading of rumours and stealing) (Cooper \& Payne, 1988; Karasek \& Theorell, 1990; Levi, 1981; Matteson \& Ivancevich, 1982; Perrewé, 1991; Quick, Quick, Nelson \& Hurrell, 1997; Wright \& Smye, 1996). The potential direct and indirect costs associated with various stressrelated consequences command more than adequate attention from the manager of any business. In the United States alone it is estimated that the overall business and industry costs associated with burned-out or dispirited employees are in the range of $\$ 150$ to $\$ 180$ billion per annum (Wright \& Smye, 1996).

In the literature many approaches exist towards the understanding of the stress-response in occupational settings, such as the PersonEnvironment Fit model (French, Kaplan \& Harrison, 1982) and the Demand-Control Model (Karasek \& Theorell, 1990). Where the former views psychological and physical stress consequences as a result of an incongruent person-environment fit, the DemandControl Model looks at the interaction between the demands of

Requests for copies should be addressed to: S Rothmann, WorkWell: Research Unit for People, Policy and Performance, Faculty of Economic \& Management Sciences, PU for CHE, Private Bag X6001, Potchefstroom, 2520 the situation and the individual's decisional freedom in terms of meeting the job requirements. Although these models influenced a considerable body of research on stress, they focus on general demands of the job and the skills and abilities of the incumbent, not taking into account the specific pressures and the role of individual differences in personality and coping resources (Spielberger \& Vagg, 1999). The transactional approach as offered by Lazarus (1991) views the interaction between the individual and his or her environment as a transaction, allowing for the individual's cognitive appraisal of stressful situations and the selective identification and utilisation of coping resources. According to Dewe, Cox and Ferguson (1993), stress is not a factor that resides in either the individual or the environment; rather it is viewed as a dynamic cognitive state where the individual interaction with the environment can be described as an ongoing transaction. In this transaction, individuals make appraisals of their encounters with their environments and attempt to cope with the issues arising from this interaction.

In terms of the current research, the stressful experience of the emergency worker is studied. Emergency work is often associated with negative health outcomes, such as an increased risk of injury, cardiovascular disease and other health problems, psychological health disorders and burnout (Grigsby \& McKnew, 1988; Hammer, Mathews, Lyons \& Johnson, 1986; Kowalski \& Vaught, 2001; Palmer, 1983). In South Africa, the context is no different. In a survey conducted by the Work Trauma Foundation in South Africa, emergency workers (ambulance personnel, technical assistants and hospital personnel) indicated safety concerns as well as physical and verbal abuse (racist comments) as major stressors in their jobs. Alarmingly, in $75 \%$ of the cases surveyed weapons were used to threaten medical personnel (Smith, 2003). When emergency workers are not able to cope with stressful events, they often experience undesirable psychological and somatic outcomes, which could lead to chronic stress, burnout and even quitting the profession (Anshel, 2000).

According to Spielberger and Vagg (1999), the identification of major sources of stress at work offers a twofold benefit for both management and employees; firstly by resulting in work environment changes that reduce stress and increase 
productivity, and secondly by facilitating the development of effective interventions that could reduce the debilitating effects of occupational stress. Meyerson (1994) and Handy (1988, 1991) showed that stress occurs in a particular context, since individuals differ in the meaning they attribute to stressful experiences. The influence of social construction of stressful experiences should also be taken into account.

Dewe (1989) adds another dimension to the measurement of stress in occupational settings by noting that the specific meaning attributed to stressful events and the perceived intensity should also be extended to include the frequency of the experienced stressor. Consequently, severity of a stressor can be obtained where an infrequently experienced stressor is not overestimated by only taking its perceived intensity into account. A further useful taxonomy of stressors in terms of their intensity and frequency is the distinction between acute and chronic stressors. Whereas an acute stressor is derived from a rather sudden event with relative short duration in which an almost immediate psychological reaction is evoked, chronic stressors are experienced frequently and intensely (Farmer, 1990; Newton, 1989).

Consequently, the study of stressors specific to the emergency worker seems imperative from a research point of view. Not only is it important to establish reliable and valid methods of measurement with regards to perceived stress, it is also important to consider cultural diversity in a multicultural setting such as South Africa. In this regard, Van de Vijver and Leung (1997) recommended that issues of measurement equivalence and bias should be computed for measuring instruments in any multicultural setting where groups from different cultural groups are compared in terms of a specific construct. This is particularly relevant where no norms exist for the different cultural groups, which is often the case in crosscultural research. In line with recommendations of Poortinga (1989) and Van de Vijver and Leung (1997), measurement equivalence and bias should be tested for in a multi-cultural context where differences in scores could be attributed to cultural influences in terms of item meaning and understanding, rather than differences resulting from the measuring of the constructs by the measuring instruments. If cultural influences are not accounted for, invalid conclusions regarding the constructs under study could be made with serious implications for culturally diverse settings such as in South Africa. Where measurement equivalence is concerned with measurement and the comparability of scores, bias is concerned with factors that influence the validity of crosscultural comparisons.

The objectives of this study were to determine the construct validity, internal consistency, construct equivalence and item bias of an occupational stress measure and to identify job stressors for emergency workers.

\section{Occupational stress}

According to Schaufeli and Bakker (2002), any occupation can be viewed from a stress perspective in terms of two elements, namely job demands and job resources. Job demands are those physical, psychological, social or organisational aspects of the job which require sustained physical and/or psychological (i.e. cognitive or emotional) effort and as a consequence are associated with physiological or psychological costs, e.g. work overload, personal conflicts and emotional demands, such as demanding clients. Although these demands are not necessarily negative, they can turn into stressors when trying to meet these high demands requires sustained effort. Consequently they become associated with negative responses in the long run, such as depression, anxiety, or burnout. Job resources, on the other hand, refer to those physical, psychological, social or organisational aspects of the job that: (1) reduce the job demands and therefore the associated physiological and psychological costs, or (2) are functional in the achievement of work goals, or, (3) stimulate personal growth, learning and development, through, for example, social support, autonomy, feedback and job security.

In a qualitative study on the stressors experienced by emergency workers (ambulance and rescue services) in a South African coastal city, Sparrius (1992) found a range of individual, intergroup and extra-organisational stressors, both unique and commonly associated with the emergency services. Interestingly, of the 19 stressors identified, almost 15 stressors could be attributed to organisational-based stressors, reflecting high levels of negativity towards the organisation. These stressors include the experience of the structure of the organisation as paramilitary, managerial favouritism and the lack of motivation which results in conflict and which in turn results in upward, downward and lateral communication problems between management and employees. Other individual stressors identified were interaction with patients, unexciting tasks, dealing with patients, slow shifts, physical danger in terms of geographical location, physical and verbal abuse from bystanders, lack of equipment, travelling long distances, shiftwork, meeting deadlines and administrative work. Some interpersonal stressors were clashing personalities at work, colleagues not accepting change and pettiness among colleagues. Some extra-organisational stressors included the perceived low occupational status of South African Health Services, remuneration in comparison with other emergency workers in South Africa, lack of suitably qualified employees and a shortage of dedicated workers.

According to Cloete (1985), five sources of stressors can be identified for high-stress occupations, such as the emergency workers, namely: the degree of uncertainty, physical reaction to the alarm signal, interpersonal tension, exposure to loss of life and fear. In a similar vein, Mitchell (1983) identified personal and work-related stress, further subdividing the workrelated stressors into those due to environmental working conditions (e.g. physical dangers such as fires, poor working relationships and lack of advancement opportunities) and those resulting from assistance of others (e.g. exposure to physical suffering, neurotic and violent people, as well as responsibility for other people's lives). Peterson, Prout and Schwartz (1991) found that paramedics regard child abuse, mass casualties, disasters, infant deaths and high rise fires as extremely traumatic stressors.

Research seems to suggest that occupational groups experience stressors in different ways. Young and Cooper (1995) conducted a study in England to assess occupational stress amongst a group of ambulance and fire services personnel. The results showed that for the ambulance group significantly more stress was reported for factors intrinsic to the job, career and achievement and organisational structure and climate when compared to the normative group. Significant differences in perceived stress were only found for the fire-fighter group in terms of their relationship with others. Analysis of variance revealed that organisational structure and climate were perceived as more stressful for the ambulance sample, whereas relationships with others produced more stress for the fire-fighter sample.

In a study on the occupational stress of primary physicians, it was found that in terms of gender, female paediatricians were less stressed than men, and family physicians' stress levels were significantly negatively related to their age (Kushnir, Cohen \& Kitai, 2000). According to Von Hallmayer, Klingbeil and KohnSeyer (1981), fire-fighters tend to evaluate risks differently and more negatively as they get older and more experienced, whereas Preuss and Schaeke (1998) found no relationship between age, experience and level of perceived strain.

The study of Pienaar and Rothmann (in press) in the South African Police Services seems to suggest that differences in the levels of perceived strain exist for language groups. More stress 
in terms of lack of job resources was found for the Afrikaans and English groups in comparison with the other groups. Also, these groups demonstrated higher levels of strain with regards to stressors inherent to police work relative to the other groups in the sample.

Accordingly, the following hypotheses were formulated:

H1: The EWSI is an internally consistent and valid measuring instrument of occupational stress of emergency workers in Gauteng.

H2: The EWSI is a structurally equivalent and unbiased measuring instrument of occupational stress for the different emergency worker language groups in Gauteng.

H3: Significant differences exist for the different occupational and language groups in terms of occupational stress.

\section{METHOD}

\section{Research design}

A cross-sectional survey design was used to reach the objectives of this research. This design is suitable for the development and validation of questionnaires (Shaughnessy \& Zechmeister, 1997).

\section{Study population}

The study population could be defined as an accidental sample of emergency workers in the different regions of Gauteng, namely West Rand, Ekurhuleni, Sedibeng, Johannesburg Metropolitan, Tshwane, Kungwini and Nokeng Tsa Taemane. The total population of about 2100 emergency workers in Gauteng was targeted. A response rate of $21,6 \%$ was achieved due to the nature of the job, e.g. call-outs, rotating working schedules and leave of which 405 responses $(19,3 \%)$ could be utilised. Language groups and positions were grouped together to facilitate analysis of the data. Language groupings are explained in a footnote, while positions were broadly grouped together as follows: Management, Medical Specialists (e.g. medical practitioners and pathologists), Emergency Medical Technicians (e.g. fire-fighters, ambulance drivers, emergency staff and paramedics) and Support Services (e.g. administration, training, assistants and support services). Descriptive information of the sample is given in Table 1 .

The sample consisted mainly of Afrikaans and Sotho-speaking emergency workers $(72,79 \%)$. They were mostly married men $(77,72 \%)$ with a tertiary education (diploma), a mean age of 33,50 years and an average length of service of 9,02 years.

\section{Measuring Battery}

The Emergency Worker Stress Inventory (EWSI) consists of 78 items and was developed for the purpose of this study. A number of research studies have been published regarding the typical stressors specific to the emergency worker (Anshel, 2000; Beaton et al., 1997; Cloete, 1985; Grigsby \& McKnew, 1988; Hammer et al., 1986; Kowalski \& Vaught, 2001; Kushnir et al., 2000; Marmar et al., 1996; Mitchell, 1983; Mitchell \& Dyregrov, 1993; Moran \& Britton, 1994; Palmer, 1983; Peterson et al., 1991; Phipps, 1988; Preuss \& Schaeke, 1998; Sparrius, 1992; Violanti \& Paton, 1999; Von Hallmayer et al., 1981; Whitley et al., 1989; Young \& Cooper, 1995). These sources were consulted in the construction of the current instrument. In line with the recommendations of Dewe (1989) and Spielberger and Vagg (1999) both the severity and frequency of stressors were addressed in the scale construction. Firstly, participants rated each of the 39 statements in terms of perceived intensity of the particular stressor on a 9-point scale, ranging from 1 (low) to 9 (high). In the second part of the questionnaire, the participants were asked to respond in terms of perceived frequency in experiencing these stressors over a period of the past six months on a 10 point scale ranging from 0 (no days) to $9+$ (more than 9 days). In each instance, the respondents are given the option to indicate whether a given stressor is relevant in terms of their experience or not.
TABLE 1

Characteristics OF PaRTICIPANTS

\begin{tabular}{|c|c|c|}
\hline Item & Category & Percentage \\
\hline \multirow[t]{7}{*}{ Home Language } & Afrikaans & 35,40 \\
\hline & English & 15,59 \\
\hline & Sotho & 27,72 \\
\hline & Nguni & 15,35 \\
\hline & Indigenous Independent Languages & es 2,23 \\
\hline & Eastern & 1,49 \\
\hline & European & 2,23 \\
\hline \multirow[t]{4}{*}{ Position } & Management & 14,22 \\
\hline & Medical Specialists & 7,11 \\
\hline & Emergency Workers & 72,79 \\
\hline & Support Services & 5,88 \\
\hline \multirow[t]{7}{*}{ Area } & West Rand & 11,62 \\
\hline & Ekurhuleni & 42,93 \\
\hline & Sedibeng & 15,66 \\
\hline & Johannesburg Metro & 11,11 \\
\hline & Tshwane & 7,32 \\
\hline & Kungwini & 10,10 \\
\hline & Nokeng Tsa Taemane & 1,26 \\
\hline \multirow[t]{4}{*}{ Education } & Grade 11 or below & 11,66 \\
\hline & Grade 12 & 20,86 \\
\hline & Tertiary education: Diploma & 41,10 \\
\hline & Tertiary education: Degree & 26,38 \\
\hline \multirow[t]{2}{*}{ Gender } & Male & 77,72 \\
\hline & Female & 22,28 \\
\hline \multirow[t]{4}{*}{ Marital status } & Single & 25,62 \\
\hline & Engaged & 10,10 \\
\hline & Married & 58,37 \\
\hline & Separated/Divorce/Death & 5,91 \\
\hline
\end{tabular}

A biographical questionnaire was also developed. Participants were given the option of providing their names and contact details in the case of feedback. Other information gathered included position, area, education, gender, marital status and language.

\section{Statistical analysis}

The statistical analysis was carried out with the aid of the SAS program (SAS Institute, 2000). Principal factor extraction with both oblique and varimax rotation were carried out by means of SAS FACTOR for the EWSI. Prior to principal factor extraction, principal component extraction was done to determine the number of factors, the presence of outliers and the factorability of the correlation matrices.

Construct (structural) equivalence was determined to compare the different language groups included in this study. Exploratory factor analysis with a Procrustean target rotation was used to determine the construct equivalence of the EWSI for the different language groups in the sample (Van de Vijver \& Leung, 1997). According to Van de Vijver and Leung (1997), the comparison between similarities of the factor structure of two cultural groups could be underestimated due to the arbitrary spatial allocation of factors during factor analysis. Rather, it is suggested that target rotation be conducted prior to comparing the factor solutions of cultural groups by rotating the factor-loading matrices with regard to each other in order to maximise the agreement between the factors. During this process, one group is arbitrarily designated as the target group and the factor loadings of the other group rotated towards the target group to form a common factor loading matrix, also know as the centroid. Factorial agreement between the two groups is then estimated with 
Tucker's coefficient of agreement, also known as Tucker's phi. Because this index is insensitive to multiplications of factor loadings, but sensitive to a constant added to factor loadings, sufficient agreement between the factor-solutions of the respective cultural groups would be a reflection of the extent to which a perfect multiplicative agreement is achieved between the factor loadings of the respective factor solutions of both groups in the centroid. The formula for Tucker's phi is as follows:

$p_{x y}=\frac{\sum x_{i} y_{i}}{\sqrt{\sum x_{i}^{2} y_{i}^{2}}}$

Because this index does not have a known sampling distribution, it is impossible to establish confidence intervals. Values higher than 0,95 are deemed to be evident of factorial similarity or equivalence across different cultural groups (Van de Vijver \& Leung, 1997), whereas values lower than 0,90 (Van de Vijver \& Poortinga, 1994) or even 0,85 (Ten Berge, 1986) should be viewed as an indication of sufficient existing differences. This index is deemed sufficiently adequate to evaluate global factorial agreement, but if construct equivalence is not acceptable, bias analysis should be conducted to detect possible inappropriate items in the questionnaire. Furthermore, bias analysis is necessary because construct equivalence does not presuppose the absence of bias. An instrument could therefore demonstrate acceptable construct equivalence and still be biased (Van de Vijver \& Leung, 1997).

In order to determine item bias, an extension of Cleary and Hilton's (1968) use of analysis of variance were used to identify possible item bias (Van de Vijver \& Leung, 1997). Bias was determined for each individual item. In the analysis, the individual item was specified as the dependent variable with language groups and score groups as the independent variables in the variance analysis. Score groups were compiled, based on the total scores on the EWSI. A total of ten score levels were obtained by using percentiles identified through SAS UNIVARIATE. Two effects were tested for significance in the subsequent variance analysis, namely the main effects of culture (uniform bias) and interaction effects of culture and score level (non-uniform bias). If both the main effect of culture and the interaction of culture and score level is found to be non-significant, the item is taken to be unbiased. If any biased items are identified in this process it would be considered inappropriate to include them in the next step, namely the principal component and factor extraction analysis.

Descriptive statistics (means, standard deviations, skewness and kurtosis) were also computed to describe the data. Cronbach alpha coefficients and inter item-correlations were used to determine the internal consistency, homogeneity and unidimensionality of the measuring instruments (Clark \& Watson, 1995). One-way analysis of variance (ANOVA) was used to determine the differences between the subgroups of the sample. Tukey's Standardised Range tests were used to determine the statistical significance of differences obtained during ANOVAs. Practical significance of the differences in means between two groups was computed with the following formula (Cohen, 1988; Steyn, 1999):

$d=\frac{\operatorname{Mean}_{A}-\operatorname{Mean}_{B}}{S D_{M A X}}$

where

$\operatorname{Mean}_{\mathrm{A}}=$ Mean of the first group

Mean $_{\mathrm{B}}=$ Mean of the second group
$S D_{\mathrm{MAX}}=$ Highest standard deviation of the two groups

The following formula was used to determine the practical significance of means of more than two groups (Steyn, 1999):

$d=\frac{\text { Mean }_{A}-\text { Mean }_{B}}{\text { Root MSE }}$

where

$\mathrm{Mean}_{\mathrm{A}}=$ Mean of the first group

Mean $_{\mathrm{B}}=$ Mean of the second group

Root MSE $=$ Root Mean Square Error

Cohen (1988) recommends the following cut-off points for practical significance:

$d=0,20-$ small effect

$d=0,50-$ medium effect

$d=0,80-$ large effect

In terms of the current research, a cut-off point of 0,50 (medium effect) was set for the practical significance of the differences between group means.

\section{RESULTS}

The results of the factor analysis of the Emergency Worker Stress Inventory (EWSI) are provided in Table 2. Variable-factor loadings, communalities and percentage variance and covariance are given. The variables are ordered and grouped according to loading-size to facilitate interpretation and loadings below 0,45 ( $21 \%$ of variance shared with the total variance of factor) were replaced with zeros. Labels for each factor are suggested in a footnote.

Inspection of Table 2 shows that three factors were extracted, accounting for $35,67 \%$ of the total variance in the data. As indicated by the SMCs, all three factors were internally consistent and well defined by the variables. The variables also seem to be reasonably well represented by this factor solution. Communality values can be described as moderate. With a cutoff point of 0,45 (sharing at least $21 \%$ of the variance in a factor) for inclusion of a variable in the interpretation of a factor, only 28 of the 39 variables were retained in the factor-loading matrix. In terms of the complexity of the factor solution, items 34,32 and 39 proved to load significantly on more than one factor. However, it was decided to keep these three items.

It was decided to continue with orthogonal or varimax rotation due to insufficient inter-factor correlations yielded during oblique rotation (Factor 2 and 3, $r=0,36$; Factor 1 and 3, $r=0,33$; Factor 1 and 2, $r=0,26)$. The first factor seems to address the lack of organisational support, in other words the lack of resources. Items included in this factor include aspects such as lack of supervisory or managerial support, not being able to get along with supervisory and managerial levels, not having enough specialised personnel, poorly motivated co-workers and colleagues not doing their jobs. The second factor seems to relate to the demands of the job, namely having to deal with constant unfamiliar emergency situations, making critical on-the-spot decisions, working on the scene of an accident and frequent changes in the intensity and demand of activities. The third factor seems to refer to inherent emergency worker stressors, namely the safety of emergency workers in terms of the danger often associated with emergency work, negative attitudes towards emergency personnel, dealing with difficult customers or patients, constant public scrutiny and often unnecessary callout and public abuse. 
TABLE 2

FACtOR LOADINGS, COMMUNALITIES $\left(\mathrm{H}^{2}\right)$, PERCENTAge VARIANCE AND COVARIANCE FOR PRINCIPAL FACTORS EXTRACTION AND VARIMAX ROTATION ON EWSI ITEMS

\begin{tabular}{|c|c|c|c|c|c|}
\hline Item & Description & $\mathrm{F}_{1}^{\mathrm{a}}$ & $\mathrm{F}_{2}$ & $\mathrm{~F}_{3}$ & $h^{2}$ \\
\hline 22 & $\begin{array}{l}\text { Poor or inadequate supervision/ } \\
\text { management }\end{array}$ & 0,61 & 0,00 & 0,00 & 0,43 \\
\hline 19 & $\begin{array}{l}\text { Lack of participation in } \\
\text { policy-making decisions }\end{array}$ & 0,59 & 0,00 & 0,00 & 0,46 \\
\hline 6 & $\begin{array}{l}\text { Inadequate support by supervisor/ } \\
\text { management }\end{array}$ & 0,57 & 0,00 & 0,00 & 0,33 \\
\hline 8 & Lack of recognition & 0,56 & 0,00 & 0,00 & 0,33 \\
\hline 20 & Inadequate salary & 0,56 & 0,00 & 0,00 & 0,41 \\
\hline 30 & Poorly motivated co-workers & 0,55 & 0,00 & 0,00 & 0,43 \\
\hline 13 & $\begin{array}{l}\text { Difficulty getting along with } \\
\text { supervisor/management }\end{array}$ & 0,54 & 0,00 & 0,00 & 0,38 \\
\hline 16 & Lack of specialised personnel & 0,54 & 0,00 & 0,00 & 0,36 \\
\hline 3 & Lack of opportunity for advancement & 0,51 & 0,00 & 0,00 & 0,29 \\
\hline 9 & Performing tasks not in job description & 0,49 & 0,00 & 0,00 & 0,40 \\
\hline 15 & Insufficient personnel to handle workload & 0,47 & 0,00 & 0,00 & 0,33 \\
\hline 26 & Budgetary constraints & 0,47 & 0,00 & 0,00 & 0,30 \\
\hline 14 & $\begin{array}{l}\text { Negative attitudes towards organisation/ } \\
\text { emergency services }\end{array}$ & 0,47 & 0,00 & 0,00 & 0,29 \\
\hline 25 & $\begin{array}{l}\text { Frequent changes from boring to } \\
\text { demanding activities }\end{array}$ & 0,00 & 0,58 & 0,00 & 0,43 \\
\hline 17 & Critical on-the-spot decisions & 0,00 & 0,57 & 0,00 & 0,42 \\
\hline 4 & $\begin{array}{l}\text { Experiencing new/unfamiliar emergency } \\
\text { situations }\end{array}$ & 0,00 & 0,55 & 0,00 & 0,33 \\
\hline 23 & $\begin{array}{l}\text { Work area dependent on emergency } \\
\text { situation }\end{array}$ & 0,00 & 0,55 & 0,00 & 0,41 \\
\hline 34 & Performing duties in dangerous situations & 0,00 & 0,53 & 0,00 & 0,53 \\
\hline 24 & Frequent interruptions & 0,00 & 0,50 & 0,00 & 0,42 \\
\hline 7 & Dealing with crisis situations & 0,00 & 0,47 & 0,00 & 0,33 \\
\hline 36 & $\begin{array}{l}\text { Negative attitudes of other health care } \\
\text { personnel towards emergency services }\end{array}$ & 0,00 & 0,00 & 0,68 & 0,53 \\
\hline 31 & $\begin{array}{l}\text { Conflicts with other departments/health } \\
\text { care providers }\end{array}$ & 0,00 & 0,00 & 0,57 & 0,40 \\
\hline 33 & $\begin{array}{l}\text { Dealing with other health care } \\
\text { professionals }\end{array}$ & 0,00 & 0,00 & 0,56 & 0,39 \\
\hline 37 & Unnecessary call-out and public abuse & 0,00 & 0,00 & 0,56 & 0,43 \\
\hline 35 & $\begin{array}{l}\text { Security risk in terms of emergency } \\
\text { geographical location }\end{array}$ & 0,00 & 0,00 & 0,54 & 0,42 \\
\hline 32 & Dealing with difficult customers/patients & 0,00 & 0,00 & 0,51 & 0,49 \\
\hline 39 & $\begin{array}{l}\text { Constant public and traumatised relative } \\
\text { scrutiny at emergency scene }\end{array}$ & 0,00 & 0,00 & 0,50 & 0,51 \\
\hline \multicolumn{2}{|c|}{ Squared Multiple Correlations (SMC) } & 0,84 & 0,78 & 0,77 & \\
\hline \multicolumn{2}{|c|}{ Percentage variance } & 14,71 & 11,22 & 9,74 & \\
\hline \multicolumn{2}{|c|}{ Percentage covariance } & 41,24 & 31,45 & 27,30 & \\
\hline
\end{tabular}

a Factor labels: $\mathrm{F}_{1}$ Lack of Resources $\mathrm{F}_{2}$ Job Demands $\mathrm{F}_{3}$ Inherent Emergency Work Stressors

Next, the construct equivalence analysis was conducted for the EWSI to determine whether the constructs are equal for all the language groups in the sample. The indigenous independent language group, the Eastern and the European language groups were excluded due to inadequate sample sizes. Exploratory factor analysis and target (Procrustean) rotation were used by rotating the factor loadings of the different language groups to one target group and estimating factorial agreement based on Tucker's coefficient of agreement (Tucker's phi). These coefficients are given in Table 3 for the different language groups.

Inspection of Table 3 shows that the Tucker's phi coefficient for the Afrikaans, English and Sotho groups to be acceptable in most instances above the 0,90 level and approaching the critical level of 0,95 . It is worth mentioning that sample size could influence these values. On the EWSI, the Nguni-group demonstrated significant inequivalence below 0,90 in terms of total congruence and in terms of Inherent Emergency Work Stressors. Even though values lower than 0,90 were obtained for the English and Sotho groups in terms of Inherent Emergency Work Stressors, the total congruence indicate significant equivalence in terms of perceived occupational stress. In summary, it can be concluded that significant construct congruence exists for the Afrikaans, English and Sotho groups in terms of perceived occupational stress, but not for the Nguni group. Consequently, in terms of subsequent analysis of the data, the Nguni group was excluded.

TABLE 3

CONSTRUCT EQUIVALENCE OF THE EWSI FOR DIFFERENT LANGUAGE GROUPS

\begin{tabular}{|c|c|c|c|c|c|c|}
\hline Group & $\mathrm{N} \mathrm{I}$ & Percentage & $\begin{array}{c}\text { Tucker's phi - } \\
\text { Lack of } \\
\text { Resources }\end{array}$ & $\begin{array}{l}\text { Tucker's phi - } \\
\text { Job Demands }\end{array}$ & $\begin{array}{c}\text { Tucker's phi - } \\
\text { Inherent } \\
\text { Emergency } \\
\text { Work Stressors }\end{array}$ & $\begin{array}{c}\text { Total } \\
\text { Congruence }\end{array}$ \\
\hline Afrikaans & 143 & 35,40 & 0,98 & 0,97 & 0,98 & 0,98 \\
\hline English & 63 & 15,59 & 0,96 & 0,87 & 0,83 & 0,90 \\
\hline Sotho & 112 & 27,72 & 0,98 & 0,94 & 0,86 & 0,94 \\
\hline Nguni & 62 & 15,35 & 0,96 & 0.91 & 0,65 & 0.86 \\
\hline
\end{tabular}

The item bias analysis was completed in the next step. The results of the individual item analysis of variance for the EWSI are presented in Table 4.

TABLE 4

ITEM BIAS ANALYSES OF THE EWSI

\begin{tabular}{lccccccccc}
\hline Item & Tot_SS & Df_g & SS_g & F_g & $\begin{array}{c}\text { Eta } \\
\text { square }\end{array}$ & Df_i & SS_i & F_i & $\begin{array}{c}\text { Eta } \\
\text { square }\end{array}$ \\
\hline Lack of Resources & & & & & & & & \\
EWSI22 & 1788,30 & 2 & 7,10 & 1,10 & 0,00 & 18 & 73,00 & 1,20 & 0,04 \\
EWSI19 & 1737,10 & 2 & 14,10 & 2,20 & 0,01 & 18 & 56,20 & 1,00 & 0,03 \\
EWSI6 & 1668,40 & 2 & 0,40 & 0,10 & 0,00 & 18 & 85,70 & 1,20 & 0,05 \\
EWSI5 & 1758,40 & 2 & 109,20 & 14,60 & $0,06^{*}$ & 18 & 70,00 & 1,00 & 0,04 \\
EWSI8 & 1960,70 & 2 & 0,00 & 0,00 & 0,00 & 18 & 102,10 & 1,30 & 0,05 \\
EWSI20 & 1682,10 & 2 & 5,90 & 0,08 & 0,00 & 18 & 54,10 & 0,90 & 0,03 \\
EWSI30 & 1790,30 & 2 & 16,80 & 2,20 & 0,01 & 18 & 91,60 & 1,30 & 0,05 \\
EWSI13 & 2113,70 & 2 & 18,90 & 2,20 & 0,01 & 18 & 65,90 & 0,90 & 0,03 \\
EWSI16 & 1847,60 & 2 & 27,50 & 3,50 & 0,02 & 18 & 37,00 & 0,50 & 0,02 \\
EWSI3 & 2124,40 & 2 & 15,40 & 1,60 & 0,01 & 18 & 95,40 & 1,10 & 0,05 \\
EWSI9 & 2040,60 & 2 & 74,60 & 9,40 & 0,04 & 18 & 90,90 & 1,30 & 0,05 \\
EWSI15 & 1631,00 & 2 & 29,60 & 4,70 & 0,02 & 18 & 62,60 & 1,10 & 0,04 \\
EWSI26 & 1928,10 & 2 & 4,60 & 0,50 & 0,00 & 18 & 50,70 & 0,60 & 0,03 \\
EWSI14 & 2021,30 & 2 & 0,60 & 0,10 & 0,00 & 18 & 101,20 & 1,30 & 0,05
\end{tabular}

Job Demands

$\begin{array}{lllcllllll}\text { EWSI25 } & 1597,10 & 2 & 8,30 & 1,30 & 0,01 & 18 & 57,10 & 1,00 & 0,04 \\ \text { EWSI17 } & 1734,80 & 2 & 5,40 & 0,90 & 0,00 & 18 & 39,9 & 0,70 & 0,02 \\ \text { EWSI4 } & 1839,10 & 2 & 52,80 & 6,80 & 0,03 & 18 & 56,30 & 0,80 & 0,03 \\ \text { EWSI23 } & 1633,50 & 2 & 5,20 & 0,90 & 0,00 & 18 & 39,30 & 0,80 & 0,02 \\ \text { EWSI34 } & 1868,50 & 2 & 23,50 & 3,30 & 0,01 & 18 & 80,70 & 1,30 & 0,04 \\ \text { EWSI24 } & 1549,20 & 2 & 14,80 & 2,60 & 0,01 & 18 & 33,50 & 0,70 & 0,02 \\ \text { EWSI7 } & 1485,80 & 2 & 4,40 & 0,80 & 0,00 & 18 & 53,60 & 1,00 & 0,04\end{array}$

Inherent Emergency Work Stressors

$\begin{array}{cccccccccc}\text { EWSI36 } & 1770,60 & 2 & 17,40 & 2,80 & 0,01 & 18 & 42,10 & 0,80 & 0,02 \\ \text { EWSI31 } & 2215,60 & 2 & 23,30 & 2,70 & 0,01 & 18 & 60,30 & 0,80 & 0,03 \\ \text { EWSI33 } & 1926,70 & 2 & 6,90 & 1,00 & 0,00 & 18 & 45,20 & 0,70 & 0,02 \\ \text { EWSI37 } & 1851,00 & 2 & 2,20 & 0,30 & 0,00 & 18 & 40,60 & 0,60 & 0,02 \\ \text { EWSI35 } & 1956,20 & 2 & 2,90 & 0,40 & 0,00 & 18 & 46,90 & 0,70 & 0,02 \\ \text { EWSI32 } & 1657,30 & 2 & 8,90 & 1,40 & 0,01 & 18 & 32,40 & 0,60 & 0,02 \\ \text { EWSI39 } & 1687,40 & 2 & 13,20 & 2,20 & 0,01 & 18 & 50,70 & 0,90 & 0,03\end{array}$

* Practically significant difference of medium effect 
According to Table 4 , a significant eta square value was obtained for item 5 (main effect, medium effect size) of the EWSI, which means that this item could be regarded as uniformly biased for the Afrikaans, English and Sotho language groups. This means that for item 5, consistent cultural effects were obtained across all score levels of the item and would therefore be excluded in the subsequent analysis.

Consequently, hypothesis 2 is not supported for the EWSI.

In the next step, descriptive statistics for the intensity, frequency and severity of the EWSI are given in Table 5. Severity is expressed as the product of intensity and frequency of stressors.

TABLE 5

DESCRIPTIVE STATISTICS OF STRESSOR INTENSITY AND FREQUENCY OF EWSI ITEMS

\begin{tabular}{|c|c|c|c|c|c|}
\hline \multirow[t]{2}{*}{ Item Description } & \multicolumn{2}{|c|}{ Intensity } & \multicolumn{2}{|c|}{ Frequency } & \multirow[t]{2}{*}{ Severity } \\
\hline & Mean & SD & Mean & $S D$ & \\
\hline $\begin{array}{l}\text { Poor or inadequate supervision/ } \\
\text { management }\end{array}$ & 5,35 & 2,54 & 4,59 & 3,36 & 24,56 \\
\hline $\begin{array}{l}\text { Lack of participation in policy- } \\
\text { making decisions }\end{array}$ & 5,58 & 2,48 & 4,69 & 3,40 & 26,17 \\
\hline $\begin{array}{l}\text { Inadequate support by supervisor/ } \\
\text { management }\end{array}$ & 5,92 & 2,44 & 5,12 & 3,36 & 30,31 \\
\hline Lack of recognition & 5,92 & 2,58 & 5,83 & 3,23 & 34,51 \\
\hline Inadequate salary & 6,70 & 2,46 & 5,98 & 3,33 & 40,07 \\
\hline Poorly motivated co-workers & 6,17 & 2,47 & 5,99 & 3,13 & 36,96 \\
\hline $\begin{array}{l}\text { Difficulty getting along with } \\
\text { supervisor/management }\end{array}$ & 4,82 & 2,68 & 4,17 & 3,39 & 20,10 \\
\hline Lack of specialised personnel & 6,41 & 2,49 & 5,79 & 3,31 & 37,11 \\
\hline Lack of opportunity for advancement & 6,10 & 2,71 & 5,28 & 3,55 & 32,21 \\
\hline Performing tasks not in job description & 5,66 & 2,60 & 5,31 & 3,37 & 30,05 \\
\hline $\begin{array}{l}\text { Insufficient personnel to handle } \\
\text { workload }\end{array}$ & 7,14 & 2,28 & 6,82 & 2,94 & 48,69 \\
\hline Budgetary constraints & 5,89 & 2,59 & 5,37 & 3,44 & 31,63 \\
\hline $\begin{array}{l}\text { Negative attitudes towards organisation/ } \\
\text { emergency services }\end{array}$ & 5,85 & 2,62 & 5,19 & 3,25 & 30,36 \\
\hline $\begin{array}{l}\text { Frequent changes from boring to } \\
\text { demanding activitie }\end{array}$ & 4,95 & 2,41 & 5,01 & 3,18 & 24,80 \\
\hline Critical on-the-spot decisions & 4,94 & 2,50 & 5,10 & 3,21 & 25,19 \\
\hline $\begin{array}{l}\text { Experiencing new/unfamiliar } \\
\text { emergency situations }\end{array}$ & 5,12 & 2,54 & 5,13 & 3,45 & 26,27 \\
\hline $\begin{array}{l}\text { Work area dependant on emergency } \\
\text { situation }\end{array}$ & 5,17 & 2,47 & 5,32 & 3,27 & 27,50 \\
\hline $\begin{array}{l}\text { Performing duties in dangerous } \\
\text { situations }\end{array}$ & 5,84 & 2,69 & 5,90 & 3,28 & 34,46 \\
\hline Frequent interruptions & 5,15 & 2,32 & 5,04 & 3,14 & 25,96 \\
\hline Dealing with crisis situations & 5,41 & 2,29 & 5,55 & 3,22 & 30,03 \\
\hline $\begin{array}{l}\text { Negative attitudes of other health } \\
\text { care personnel }\end{array}$ & 5,88 & 2,53 & 5,20 & 3,24 & 30,57 \\
\hline $\begin{array}{l}\text { Conflicts with other departments/ } \\
\text { health care providers }\end{array}$ & 5,14 & 2,75 & 4,24 & 3,31 & 21,79 \\
\hline $\begin{array}{l}\text { Dealing with other health care } \\
\text { professionals }\end{array}$ & 5,06 & 2,62 & 5,17 & 3,32 & 26,16 \\
\hline Unnecessary call-out and public abuse & 6,41 & 2,61 & 6,29 & 3,21 & 40,32 \\
\hline $\begin{array}{l}\text { Security risk in terms of emergency } \\
\text { geographical location }\end{array}$ & 5,71 & 2,67 & 5,45 & 3,30 & 31,12 \\
\hline Dealing with difficult customers/patients & 5,63 & 2,47 & 5,98 & 3,03 & 33,67 \\
\hline $\begin{array}{l}\text { Constant public and traumatised } \\
\text { relative scrutiny }\end{array}$ & 5,51 & 2,51 & 5,30 & 3,16 & 29,20 \\
\hline
\end{tabular}

According to Table 5 stressors experienced by emergency workers in terms of highest severity are related to insufficient personnel to handle the workload, unnecessary call-out and abuse by the public, inadequate remuneration, lack of specialised personnel, poorly motivated co-workers, performing duties in dangerous situations, lack of recognition, dealing with difficult customers or patients and lack of opportunity for advancement.
In terms of the intensity of stressors experienced by emergency workers, the following items proved to be very stressful, namely insufficient personnel to handle the workload, unnecessary call-out and abuse by the public, lack of specialised personnel, inadequate remuneration, inadequate support by supervisor or management, lack of recognition, budgetary constraints and negative attitudes towards the organisation or the emergency services.

In terms of the regular experience of stressors, the following stressors proved to be experienced very regularly, namely insufficient personnel to handle the workload, unnecessary call-out and abuse by the public, poorly motivated co-workers, inadequate remuneration, dealing with difficult customers or patients, performing of duties in dangerous situations, lack of recognition, lack of specialised personnel and dealing with crisis situations.

Emergency workers in Gauteng reported moderate levels of intensity and frequency with regards to the following aspects:

- Budgetary constraints

- Security risk in terms of geographical location

- Negative attitudes of other health care personnel towards the emergency services

- Negative attitudes towards the organisation or the emergency services

- Inadequate support by supervisor or management

- Performance of tasks not in job description

- Dealing with crisis situations

- Constant public and traumatised-relative scrutiny while performing service

- Work area dependent on the emergency situation

- Experiencing of new or unfamiliar emergency situations.

Emergency workers seem to experience the lowest levels of stress with regards to conflicts with other departments or health care providers and also with regards to difficulty in getting along with supervisor or management.

The descriptive statistics, alpha coefficients and mean inter-item correlation coefficients for the extracted factors of the EWSI are reported in Table 6 .

TABLE 6

Descriptive STATISTICS, AlPHa COEFficients AND MEAN INTERITEM CORRELATION COEFFICIENTS OF THE EWSI

\begin{tabular}{lcccccc}
\hline Item & Mean & SD & Skewness & Kurtosis & r(Mean) & $\alpha$ \\
\hline Lack of Resources & 83,86 & 22,17 & $-0,46$ & $-0,04$ & 0,34 & 0,88 \\
Job Demands & 36,58 & 11,93 & $-0,01$ & $-0,47$ & 0,39 & 0,82 \\
$\begin{array}{l}\text { Inherent Emergency } \\
\text { Work Stressors }\end{array}$ & 39,33 & 12,86 & $-0,33$ & $-0,02$ & 0,42 & 0,83 \\
\hline
\end{tabular}

Table 6 shows that the three extracted factors of the EWSI are normally distributed in the sample. Also, coefficient alphas for the three factors compare well with the guideline of 0,70 (Nunnally \& Bernstein, 1994). The mean inter-item correlations of the factors are well within the guideline of 0,15 $<r<0,50$ (Clark \& Watson, 1995). These results provide support for hypothesis 1 in terms of internal consistency and validity of the newly developed EWSI for the emergency worker in Gauteng.

The differences for various biographical groups were analysed in terms of perceived strain (job demands or stressors) of emergency workers. The differences in the EWSI for the different positions are given in Table 7. 
TABLE 7

DIFFERENCES IN EWSI FOR POSITIONS

\begin{tabular}{lcccccc}
\hline Item & $\begin{array}{c}\text { Management } \\
(\mathbf{1})\end{array}$ & Medical & $\begin{array}{c}\text { Emergency } \\
\text { Specialists } \\
(2)\end{array}$ & $\begin{array}{c}\text { Support } \\
\text { Workers }\end{array}$ & $\begin{array}{c}\text { Root } \\
\text { Services } \\
(3)\end{array}$ & $\begin{array}{c}\boldsymbol{p} \\
\text { MSE } \\
(4)\end{array}$ \\
\hline $\begin{array}{l}\text { Lack of } \\
\text { Resources }\end{array}$ & 87,41 & 77,41 & 84,08 & 76,75 & 22,13 & 0,18 \\
Job Demands & $36,82^{\mathrm{b}}$ & $30,71^{\mathrm{a}}$ & $37,48^{\mathrm{b}}$ & $29,80^{\mathrm{a}}$ & 11,76 & $0,01^{*}$ \\
$\begin{array}{l}\text { Inherent } \\
\begin{array}{l}\text { Emergency } \\
\text { Work Stressors }\end{array}\end{array}$ & 36,72 & 36,41 & $41,04^{\mathrm{c}}$ & $29,60^{\mathrm{a}}$ & 12,55 & $0,00^{*}$ \\
\hline
\end{tabular}

* Statistically significant difference $(\mathrm{p}<0,05)$ where letter in superscript indicates differences from other positions

a Practically significant difference between means of positions (small), b (practical significance of medium effect, $\mathrm{d}>0,50$ ) or $\mathrm{c}$ (practical significance of large effect, $d>0,80)$

Table 7 shows that emergency workers and management scored significantly higher than support services (practically significant, medium effect) and medical specialists in terms of Job Demands. Emergency workers also obtained significantly higher scores than support services on Inherent Emergency Work Stressors (practically significant, large effect).

Lastly, the differences in the EWSI for the different language groups are given in Table 8 .

TABLe 8

DIFFERENCES IN EWSI FOR LANGUAGE GROUPS

\begin{tabular}{lccccc}
\hline Item & Afrikaans (1) & English (2) & Sotho (3) & Root MSE & $\boldsymbol{p}$ \\
\hline Lack of Resources & 86,30 & 86,07 & 79,95 & 21,86 & 0,05 \\
Job Demands & 35,88 & 34,76 & 38,55 & 11,87 & 0,08 \\
$\begin{array}{l}\text { Inherent Emergency } \\
\text { Work Stressors }\end{array}$ & 38,26 & 41,89 & 39,55 & 12,75 & 0,17 \\
\hline
\end{tabular}

* Statistically significant difference $(p<0,05)$ where letter in superscript indicates differences from other positions

According to Table 8, no significant differences were found between the means of the language groups in terms of perceived strain. Consequently, these findings provide partial support for the acceptance of hypothesis 3 on the basis of significant differences obtained for positions, but not for language groups.

\section{DISCUSSION}

It was the aim of this study to develop and validate the EWSI for the emergency worker in Gauteng. A 3-factor solution, (consisting of Lack of Resources, Job Demands and Inherent Emergency Work Stressors) describing the perceived strain of emergency workers, fitted the data the best. The extracted factors can be broadly related to the results of similar studies in other contexts (Alexander, Walker, Innes \& Irving, 1993; Biggam, Power, MacDonald, Carcary \& Moodie, 1997; Brown \& Campbell, 1990, 1994; Pienaar \& Rothmann, in press). Satisfactory internal consistency and unidimensionality was obtained for the EWSI, pointing to the utility of the instrument developed for the current research.

Regarding cross-cultural group comparison, evidence of inequivalence was found for the EWSI with regards to the Nguni language group in the present study. Also, evidence of uniform bias were found for item 5 ("Fellow workers not doing their job"), which means that systematic differences in the means of the Afrikaans, English and Sotho groups were obtained for this item. This means that even though similar total scores on this item can be obtained for members of these groups, systematic differences consistently above (or below) zero were found for individual group members. These differences are caused by the group membership (cultural influences) and not ascribed to valid individual differences in terms of responses to items. This finding could be attributed to the fact that a stratified random sample was not used in the present study and that the sample size, specifically in the case of the subgroups (language groups), was significantly smaller. Insufficient subgroup sizes could cause artificial differences between subgroups.

In terms of the acuteness of perceived strain, emergency workers reported that the stressors most experienced by them in their current jobs are mostly related to a lack of organisational support. These stressors include a lack of job resources, such as insufficient personnel to handle the workload, inadequate remuneration, co-workers not doing their jobs, a lack of specialised personnel, poorly motivated co-workers, a lack of recognition and a lack of opportunity for advancement. Highly strenuous aspects related to inherent job characteristics unique to emergency work included unnecessary call-out and abuse by the public, as well as having to deal with difficult customers or patients, while factors associated with high strain in terms of the demands of the job were associated with having to perform duties in dangerous situations. It is disconcerting that most of the stressors reported by emergency workers in the present study are associated with aspects that the organisations are capable of doing something about. Despite the fact that research showed incumbents of highly stressful occupations, such as the police services and emergency work, regard stressful occupational events as being unchangeable (Violanti \& Paton, 1999), these organisational stressors might nevertheless be more easily addressed than inherent ones (Gulle, Tredoux \& Foster, 1998).

Contrary to the findings of Pienaar and Rothmann (in press) where most of the reported stressors could be categorised in the medium to low frequency categories, most of the reported stressors for emergency workers showed average to high levels of intensity and frequency. Possibly this could also be a reflection of sampling size and methods utilised in the different studies. In the present study, chronic stressors (average intensity and frequency) were mostly associated with the typical demands placed on the emergency workers by the job, but also by the lack of organisational support in terms of job resources and the inherent characteristics unique to the emergency worker context. Typical chronic stressors reported in the current study were related to dealing with crisis situations, the dependence of the work area on the emergency situation, security concerns of the emergency worker, the experience of negative attitudes and the experience of new or unfamiliar emergency situations. These findings also echo those found with police members in South Africa (Pienaar \& Rothmann, in press).

In terms of differences between groups regarding stressful experiences, it was found that emergency workers and their managers scored significantly higher than support staff with regards to the demands placed on them by the job, as well as by the unique characteristics associated with emergency work. This finding is understandable since many of the support staff are not exposed to the inherently stressful experiences of emergency workers.

No significant differences were found in terms of experienced strain for the different language groups in the present study, which is contrary to the findings of Pienaar and Rothmann (in press), where significantly higher levels of lack of resources and stressors inherent to the police service were found for the English and Afrikaans groups.

Limitations of the present study include sample size $(N=323)$, which has been reduced due to obtained inequivalence of the Nguni-group in terms of perceived strain in the present study. Also, inadequate subgroup sample sizes in terms of the 
respective language groups could significantly influence the findings. For instance during the bias analysis, the recommended number of observations per score level $(n=50)$ for each item could not be reached. Also, the sampling procedure in the present study has significant limitations in terms of the generalisation of the findings to the total study population. Future studies could benefit in terms of a stratified random-sample design which would ensure sufficient representation of the different groups in the total population of emergency workers. In terms of the research design, future studies should also focus on longitudinal designs where inferences in terms of cause and effect could be made.

\section{RECOMMENDATIONS}

In terms of perceived strain, this study is a first step towards the development of a comprehensive perceived strain profile of emergency workers in South Africa. As such, the current study only considered the Gauteng Province and it is recommended that the study be expanded to the other eight provinces in South Africa as well, specifically with the aid of randomised sampling design. In terms of stress research in the emergency services it is also important to take a holistic approach in terms of the both the work and non-work domains of the emergency worker (Cooper, Dewe \& O'Driscoll, 2001) in future research. Also, further refining and testing of the EWSI is needed in other emergency worker samples, possibly even in other African countries. Furthermore, criterion-related validity studies are also necessary to establish the validity of this instrument, using it in conjunction with existing tests to determine its concurrent validity.

In terms of the experience of stressors by emergency workers, the high incidence of lack of support by the organisation in terms of resources is a concern. If these stressors are allowed to continue unattended, the organisation can expect to find negative costs associated with continued, elevated levels of stress, such as burnout, employee turnover and lowered levels of service. The organisation is therefore advised to prioritise the issue of staff shortages and the motivational aspect of workers by means of the recruitment of specialised personnel, the filling of vacant positions and reviewing of the remuneration structures of emergency workers by means of benchmarking initiatives.

Furthermore, with regards to motivation of co-workers and the lack of recognition reported by emergency workers, it is recommended that the organisation should consider an intervention aimed at maximising group effectiveness. A leadership skills intervention aimed at first-line management could also be considered in the different regions in this regard. Considering the decentralised nature of management within the different regions, as well as the significant changes that are taking place within national government structures, it is recommended that a change management initiative be considered.

Finally, it is recommended that with regards to the perceived strain of emergency workers in South Africa, that construct equivalence and item bias should be computed in line with the recommendations of Van de Vijver and Leung (1997).

\section{REFERENCES}

Alexander, D.A., Walker, L.G., Innes, G. \& Irving, B.L. (1993). Police stress at work. London: Police Foundation.

Anshel, M.H. (2000). A conceptual model and implications for coping with stressful events in police work. Criminal Justice and Behavior, 27, 375-400.

Beaton, R.D., Murphy, S.A., Pike, K.C. \& Corniel, W. (1997). Social support and network conflict in fire-fighters and paramedics. Western Journal of Nursing Research, 19, 297-313.
Biggam, F.H., Power, K.G., MacDonald, R.R., Carcary, W.B. \& Moodie, E. (1997). Self-perceived occupational stress in a Scottish police force. Work and Stress, 11, 118-133.

Brown, J.M. \& Campbell, E.A. (1990). Sources of occupational stress in the police. Work and Stress, 4, 305-318.

Brown, J.M. \& Campbell, E.A. (1994). Stress and policing: Sources and strategies. Chichester, UK: Wiley.

Clark, L.A. \& Watson, D. (1995). Constructing validity: Basic issues in objective scale development. Psychological Assessment, 7, 309-319.

Cleary, T.A. \& Hilton, T.L. (1968). An investigation of item bias. Educational and Psychological Measurement, 28, 61-75.

Cloete, A.F. (1985). Stress: The number 1 killer. Fire \& Civil Defence, 18-19.

Cohen, J. (1988). Statistical power analysis for the behavioral sciences ( $2^{\text {nd }}$ ed.). Hillside, NJ: Erlbaum.

Cooper, C.L. \& Payne, R. (Eds.). (1988). Causes, coping and consequences of stress at work. Chichester, UK: Wiley.

Cooper, C.L., Dewe, P.J. \& O'Driscoll, M.P. (2001). Organizational stress: A review and critique of theory, research and applications. Thousand Oaks, CA: Sage.

Dewe, P.J. (1989). Examining the nature of work stress: Individual evaluations of stressful experiences and coping. Human Relations, 42, 993-1013.

Dewe, P.J., Cox, T. \& Ferguson, E. (1993). Individual strategies for coping with stress and work: A review. Work and Stress, 7, 515 .

Farmer, R.E. (1990). Clinical and managerial implications of stress research on the police. Journal of Police Science and Administration, 17, 203-218.

French, J.R.P., Jr., Caplan, R.D. \& Harrison, R.V. (1982). The mechanisms of job stress and strain. Chichester, UK: Wiley.

Grigsby, D.W. \& McKnew, M.A. (1988). Work-stress burnout among paramedics. Psychological Reports, 63, 55-64.

Gulle, G., Tredoux, C. \& Foster, D. (1998). Inherent and organisational stress in the SAPS: An empirical survey in the Western Cape. South African Journal of Psychology, 28, 129134.

Hammer, J.S., Mathews, J.J., Lyons, J.S. \& Johnson, N.J. (1986). Occupational stress within the paramedic profession: An initial report of stress levels compared to hospital employees. Annals of Emergency Medicine, 15, 536-539.

Handy, J.A. (1988). Theoretical and methodological problems within occupational stress and burnout research. Human Relations, 41, 351-369.

Handy, J.A. (1991). Stress and contradiction in psychiatric nursing. Human Relations, 44, 39-53.

Karasek, R.A. \& Theorell, T. (1990). Healthy work: Stress, productivity and the reconstruction of working life. New York: Wiley.

Kowalski, K.M. \& Vaught, C. (2001). The safety and health of emergency workers. Journal of Contingencies \& Crisis Management, 9 (3), 138-143.

Kushnir, T., Cohen, A.H. \& Kitai, E. (2000). Continuing medical education and primary physician's job stress, burnout and dissatisfaction. Medical Education, 34, 430-436.

Lazarus, R.S. (1991). Psychological stress in the workplace. In P.L. Perrewé (Ed.), Handbook on job stress (pp. 1-13). Corte Madera, CA: Select Press.

Levi, L. (1981). Preventing work stress. Reading, MA: AddisonWesley.

Marmar, C.R., Weis, D.S., Metzler, T.J., Ronfeldt, H.M. \& Foreman, C. (1996). Stress responses of emergency service personnel to the Loma Prieta earthquake Interstate 880 freeway collapse and control traumatic incidents. Journal of Traumatic Stress, 9, 63-85.

Matteson, M.T. \& Ivancevich, J.M. (1982). Managing job stress and health: The intelligent person's guide. New York: The Free Press.

Meyerson, D.E. (1994). Interpretations of stress in institutions: The cultural production of ambiguity and burnout. Administrative Science Quarterly, 39, 628-653. 
Mitchell, J.T. \& Dyregrov, A. (1993). Traumatic stress in disaster workers and emergency personnel: Prevention and intervention. In J.P. Wilson \& B. Raphael (Eds.), International Handbook of Traumatic Stress Syndromes. New York: Plenum Press.

Mitchell, J.T. (1983). Emergency medical stress. Associated Public Safety Communication Officers Bulletin, 14-15.

Moran, C. \& Britton, N.R. (1994). Emergency work experience and reactions to traumatic incidents. Journal of Traumatic Stress, 7, 575-585.

Newton, T.J. (1989). Occupational stress and coping with stress: A critique. Human Relations, 42, 441-461.

Nunnally, J.C. \& Bernstein, I.H. (1994). Psychometric theory (3rd ed.). New York: McGraw-Hill.

Palmer, C.E. (1983). A note about paramedics' strategies for dealing with death and dying. Journal of Occupational Psychology, 56, 83-86.

Perrewé, P.L. (Ed.). (1991). Handbook on job stress. Corte Madera, CA: Select Press.

Peterson, K.C., Prout, M.F. \& Schwartz, R.A. (1991). Post Traumatic Stress Disorder: A clinician's guide. New York: Plenum Press.

Phipps, L. (1988). Stress among doctors and nurses in the emergency department of a general hospital. Canadian Medical Association Journal, 139, 375-376.

Pienaar, J. \& Rothmann, S. (in press). Job stress in the South African Police Service. Manuscript submitted for publication.

Poortinga, Y.H. (1989). Equivalence of cross-cultural data: An overview of basic issues. International Journal of Psychology, $24,737-756$

Preuss, G. \& Schaeke, G. (1998). Firefighters exposed to psychomental stress and hazardous work situations. Poster presented at the Work, Health and Stress Conference, Institut für Arbeitsmedizin der Freien Universität, Berlin, Germany.

Quick, J.C., Quick, J.D., Nelson, D.L. \& Hurrell, J.J. (1997). Preventative stress management in organisations. Washington, DC: American Psychological Association.

SAS Institute. (2000). The SAS System for Windows: Release 8.01. Cary, NC: SAS Institute Inc.

Schaufeli, W.B. \& Bakker, A.B. (2002). Job demands, job resources and their relationship with burnout and engagement: A multisample study on the COBE-model. Manuscript made available by authors.
Schaughnessy, J.J. \& Zechmeister, E.B. (1997). Research methods in psychology (4th ed.). New York: McGraw-Hill.

Smith, E. (2003, April 6). Hospitale nou oorloggebiede [Hospitals now war-zones]. Gauteng Rapport, pp. A1.

Sparrius, S.K. (1992). Occupational stressors among ambulance and rescue service workers. South African Journal of Psychology, 22, 87-91.

Spielberger, C.D. \& Vagg, P.R. (1999). Job Stress Survey: Professional manual. Odessa, FL: Psychological Assessment Resources.

Steyn, H.S. (1999). Praktiese betekenisvolheid: Die gebruik van effekgroottes [Practical significance: Use of effect sizes]. (Scientific contributions, Series B, Natural Sciences, No. 117). Potchefstroom, South Africa: Potchefstroom University for Christian Higher Education, Statistical Consultation Services.

Ten Berge, J.M.F. (1986). Rotatie naar perfecte congruentie en de Multipele Groep Methode [Rotation towards perfect congruence and the Multi-Group Method]. Nederlands Tijdschrift voor de Psychologie, 41, 218-225.

Van de Vijver, F. \& Leung, K. (1997). Methods and data analysis for cross-cultural research. Thousand Oaks, CA: Sage.

Van de Vijver, F. \& Poortinga, Y.H. (1994). Methodological issues in cross-cultural studies on parental rearing behavior and psychopathology. In C. Perris, W.A. Arrindell \& M. Eisemann (Eds.), Parental rearing and psychopathology (pp. 173-197). Chichester, UK: Wiley.

Violanti, J.M. \& Paton, D. (Eds). (1999). Police trauma: Psychological aftermath of civilian combat. Springfield, IL: Charles C. Thomas.

Von Hallmayer, A., Klingbeil, M. \& Kohn-Seyer, G. (1981) Physische und psychische belastungskomponenten in der tätigkeit des feuerwehrmannes [Physical and psychological overloading of fire-fighters]. Zeitschrift fur die Gesamte Hygiene und Ihre Grenzgebiete, 27 (3), 191-194.

Whitley, T.W., Gallery, M.E., Allison, E.J. \& Revicki, D.A. (1989). Factors associated with stress among emergency medical residents. Annual Emergency Medical, 18, 1157-1161.

Wright, L.A. \& Smye, M.D. (1996). Corporate abuse: How lean and mean robs people and profits. New York: Macmillan.

Young, K.M. \& Cooper, C.L. (1995). Occupational stress in the ambulance service: A diagnostic study. Journal of Managerial Psychology, 10 (3), 29-36. 